\title{
Analysis of T-Slot Loaded Disk Patch Antenna for Dual Band Operation with Small Frequency Ratio
}

\author{
J. A. Ansari and Sapna Verma \\ Department of Electronics and Communication, University of Allahabad, \\ Allahabad-211002, Uttar Pradesh, India \\ Corresponding Author: sverma.ece@gmail.com
}

\begin{abstract}
In this article, a dual band patch antenna is achieved by introducing T-slot in circular disk with small frequency ratio. It is theoretically investigated using equivalent circuit theory concept. The resonance frequency is found to be 1.84 and $2.02 \mathrm{GHz}$ suitable for DCS-1800, PCS-1900 and IMT-2000 applications. The measured bandwidths at lower and upper resonances are found to be $6.59 \%$ and $6.89 \%$ respectively for proposed antenna specifications. The effect of slots dimension in the patch is studied. The frequency ratio is found to be 1.09. The maximum gain of the proposed antenna is found to be 6.52 dBi whereas efficiency is found to be $62.17 \%$ and $76.42 \%$ at lower and upper resonance frequencies respectively. The theoretical results are compared with simulated and measured results and they are in good agreement.
\end{abstract}

Keywords: Circular disk patch antenna, dual band antenna, microstrip patch antenna, T-shaped slot.

\section{Introduction}

The dual-frequency circular microstrip antennas are one of the most promising technologies in the wireless communication due to their low profile, reduction in size, easy of fabrication, integrability with millimeter and microwave circuits. Dualband antennas are being used in large variety of applications such as Global System for Mobile (GSM), Digital Cordless System (DCS-1800), Personal Communication System (PCS1900) and International Mobile Communication (IMT-2000) for mobile communication system [1-2]. In the last two decades, the numerous techniques reported to obtain dualfrequency behavior including radar cross section reduction method is based on the absorbing metamaterial loaded around the patch [3], U-slot with L-strip feeding techniques [4], truncated tip triangular is embedded with a V-slot shorted patch antenna [5], meandered line feed in trapezoidal antenna [6] and tunable two varactor loaded patch [7]. However, these techniques make antenna more complicated. A simple method to achieve the dual band operation is by reactively loading the patch. This is done by the way of cutting two L-shaped slots in disk patch [8], rounded corner triangular patch antenna [9], dome shaped array microstrip patch antenna [10]. The loading of the slot on the patch increases the current path length that results in lowering the antenna resonance frequency which corresponds to reduced antenna size.

However, these reported antenna structures of reactive loading using slots [11-19] involve complex calculation, design, higher frequency ratio and lower bandwidth as compared to proposed antenna. This has been summarized in Table 1. This innovate us to work on dual band T-slot loaded disk patch antenna which can overcome above limitations. The analysis of the proposed antenna is carried out using circuit theory concept based on modal expansion cavity model. Various parameters such as return loss, gain, efficiency and radiation pattern of the proposed antenna have been investigated. The details are discussed in following section. 
Table 1. Comparisons of Antenna Size, Bandwidth and Frequency Ratio of the Proposed Antenna with Other Antennas

\begin{tabular}{|c|c|c|c|c|c|c|c|}
\hline $\begin{array}{c}\text { S. } \\
\text { No. }\end{array}$ & References & $\begin{array}{c}\text { Antenna } \\
\text { Size }(\mathbf{m m})\end{array}$ & $\begin{array}{c}\mathbf{f}_{\mathbf{L}} \\
(\mathbf{G H z})\end{array}$ & $\begin{array}{c}\text { Bandwidth } \\
(\boldsymbol{\%})\end{array}$ & $\begin{array}{c}\mathbf{f}_{\mathbf{H}} \\
(\mathbf{G H z})\end{array}$ & $\begin{array}{c}\text { Bandwidth } \\
(\mathbf{\%})\end{array}$ & $\mathbf{f}_{\mathbf{H}} / \mathbf{f}_{\mathbf{L}}$ \\
\hline 1 & Ref. [11] 2006 & $22.5 \times 29.4$ & 2.5 & 4.0 & 4.65 & 6.66 & 1.86 \\
\hline 2 & Ref. [12] 2007 & $50 \times 50$ & 2.85 & 4.78 & 3.8 & 9.0 & 1.68 \\
\hline 3 & Ref. [13] 2008 & $17 \times 18$ & 1.42 & 4.3 & 4.40 & 4.06 & 3.09 \\
\hline 4 & Ref. [14] 2009 & $33.5 \times 12.5$ & 2.45 & 4.5 & 5.8 & 6.4 & 2.36 \\
\hline 5 & Ref. [15] 2010 & $50 \times 50$ & 1.99 & 4.0 & 2.2 & 2.5 & 1.1 \\
\hline 6 & Ref. [16] 2011 & $50 \times 50$ & 3.5 & 1 & 5.8 & 3.1 & 1.66 \\
\hline 7 & Ref. [17] 2012 & $30 \times 40$ & 4.17 & 5.28 & 5.78 & 2.27 & 1.38 \\
\hline 8 & Ref. [18] 2013 & $184 \times 134$ & 2.1 & 2.4 & 3.5 & 2 & 1.66 \\
\hline 9 & Ref. [19] 2014 & $40 \times 80$ & 2.44 & 3.68 & 5.25 & 3.80 & 2.15 \\
\hline 10 & Proposed antenna & $30 \times 30$ & 1.835 & 6.59 & 2.016 & 6.89 & 1.097 \\
\hline
\end{tabular}

\section{Antenna Design and Its Equivalent Circuits}

Figure 1 shows the top view and side view configurations of the T-slot loaded disk patch antenna with current distribution at the lower and upper resonance frequency. The analysis of proposed antenna is carried out by considering the disk patch of radius ' $a$ ' equivalent to the square patch of side $2 a$ [20].

The T-slot is etched on a radiating circular patch which is fabricated over dielectric substrate of relative dielectric constant $\varepsilon_{r}=4.4$ and thickness $h=1.6 \mathrm{~mm}$. The proposed antenna is excited by a $50 \Omega$ coaxial feed. A T-slot of dimension $L_{v s} \times L_{h s} \times T$ is incorporated in the centre of the patch so that the vertical and horizontal slots are symmetrically and perpendicular to each other. The first slot is vertical slot with dimension $L_{v s} \times T$ and the second slot is horizontal slot with dimension $L_{h s} \times T$. Figure 1 (c) shows the fabricated photo of the proposed antenna with design specifications which is shown in Table 2.

Table 2. Design Specifications for T-slot Loaded Circular Patch Antenna

\begin{tabular}{ll}
\hline Parameters & Values \\
\hline Substrate material & FR4 \\
Relative permittivity of the substrate $\left(\varepsilon_{r}\right)$ & 4.4 \\
Thickness of the dielectric substrate $(h)$ & $1.6 \mathrm{~mm}$ \\
Radius of the disk patch $(a)$ & $15.0 \mathrm{~mm}$ \\
Length of the vertical slot $\left(L_{v s}\right)$ & $18.0 \mathrm{~mm}$ \\
Length of the horizontal slot $\left(L_{h s}\right)$ & $18.0 \mathrm{~mm}$ \\
Thickness of the slots $(T)$ & $2.0 \mathrm{~mm}$ \\
Feed location $\left(x_{0}, y_{0}\right)$ & $(1.55,-6.825)$ \\
\hline
\end{tabular}




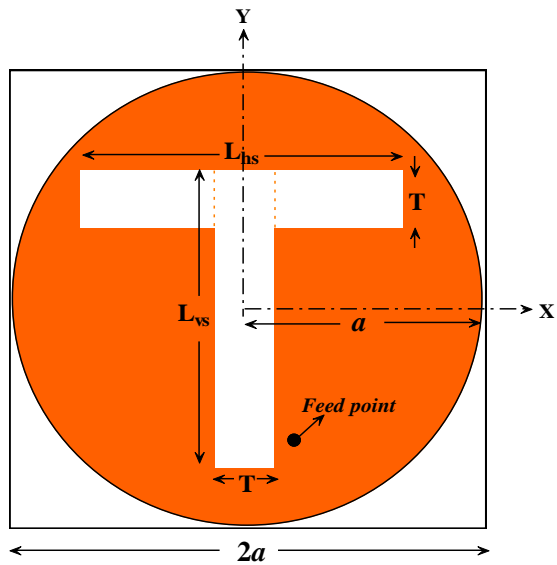

(a)

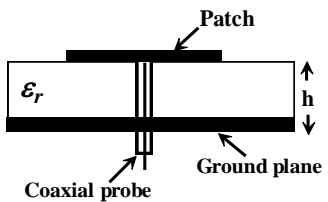

(b)

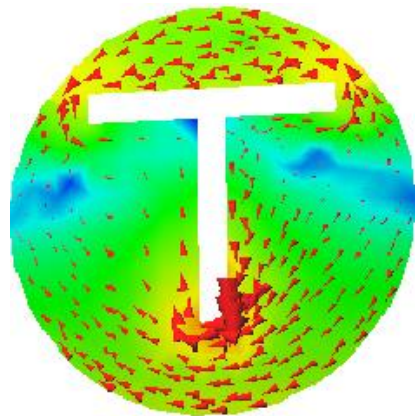

(d)

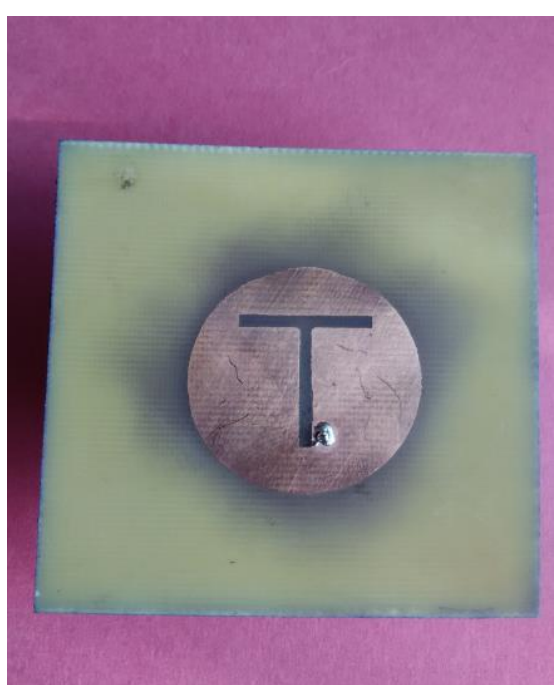

(c)

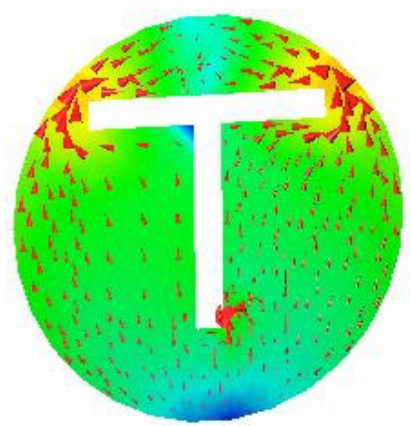

(e)

Figure 1. Antenna Geometry (a) Top View (b) Side View (c) Fabricated Photo of the Proposed Antenna and its Current Distribution for Lower and Upper Resonance Frequency (d) $f_{r 1}=1.84 \mathrm{GHz}$. (e) $f_{r 2}=2.02 \mathrm{GHz}$

The equivalent circuit of the circular patch antenna is shown in Figure 2 in which the circuit parameters are considered as a parallel combination of resistance $\left(R_{l}\right)$, inductance $\left(L_{l}\right)$ and capacitance $\left(C_{l}\right)$. The approximate values of these parameters can be calculated as [1]

$$
\begin{gathered}
R_{1}=\frac{h^{2} E_{0}^{2} j_{n}^{2}\left(k x_{0}\right)}{2 P_{T}} \\
L_{1}=\frac{R_{1}}{2 \pi f_{r} Q_{T}} \\
C_{1}=\frac{Q_{T}}{2 \pi R f_{r}}
\end{gathered}
$$

where, $J_{n}\left(k x_{0}\right)=$ Bessel functions of order ' $\mathrm{n}$ ', $x_{0}=$ feed point location along $x$-axis of the disk patch, $h=$ substrate thickness, $Q_{T}=$ total quality factor of the resonator, $P_{T}=$ total power loss in the cavity and $f_{r}=$ resonant frequency of the disk antenna. 


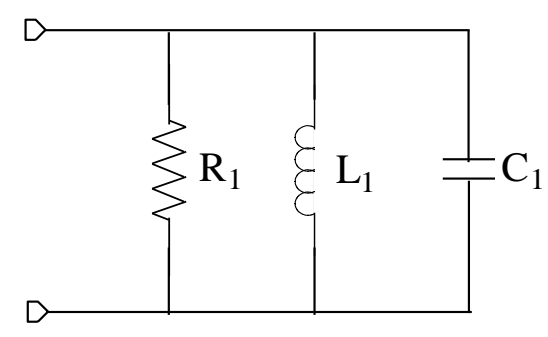

Figure 2. Equivalent Circuit of the Circular Disk Patch Antenna

The quality factor $Q_{T}$ of the antenna is calculated as

$$
Q_{T}=\frac{c \sqrt{\varepsilon_{\text {eff }}}}{4 f h}
$$

in which, $c=$ velocity of light, $f=$ design frequency

$\varepsilon_{\text {eff }}$ is effective permittivity of the medium which is given as

$$
\varepsilon_{\text {eff }}=\frac{\varepsilon_{r}+1}{2}+\frac{\varepsilon_{r}-1}{2}\left(1+\frac{10 h}{2 a}\right)^{-1 / 2}
$$

The resonance frequency of circular disk patch is given as [20]

$$
f_{r}=\frac{k_{m n} c}{2 \pi a_{\text {eff }} \sqrt{\varepsilon_{r}}}
$$

in which, $k_{m n}=m^{\text {th }}$ zero order of the derivative of Bessel function of order ' $\mathrm{n}$ ', $a_{e f f}=$ effective radius of circular disk [21]

Therefore, the impedance of the patch without T-slot can be derived from Figure 2.

$$
Z_{P}=\frac{1}{\frac{1}{R_{1}}+\frac{1}{j \omega L_{1}}+j \omega C_{1}}
$$

Slot on the patch can be analyzed by using the duality relationship between the dipole and slot [22]. T-slot can be considered as a combination of two slots as shown in Figure 1(a). Among these, two slots are perpendicular to each other. One slot is the arm length $\left(L_{v s}\right)$ of T-slot and it is vertical. The second slot is base length $\left(L_{h s}\right)$ of the T-slot and it is horizontal. As the equivalent circuit of a narrow slot comprise a series combination of the radiation resistance $\left(R_{S}\right)$ and the reactive components (XS) are shown in Figure 3(a) and 3(b).

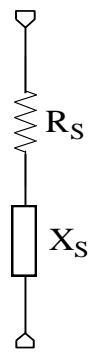

(a)

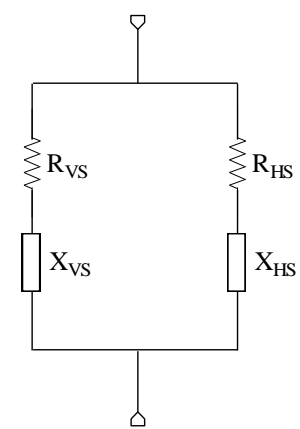

(b)

Figure 3. (a) Equivalent Circuit of a Slot, (b) Modified Equivalent Circuit of TSlot 
Therefore, the impedance of vertical slot can be determined as [23]

$$
Z_{V S}=R_{V S}+j X_{V S}
$$

where

$$
R_{V S}=60\left[\begin{array}{c}
C+\ln \left(k L_{V}\right)+\frac{1}{2} \sin \left(k L_{V}\right)\left[S_{i}\left(2 k L_{V}\right) 2 S_{i}\left(k L_{V}\right)\right] \\
+\frac{1}{2} \cos \left(k L_{V}\right)\left[C+\ln \frac{k L_{V}}{2} C_{i}\left(2 k L_{V}\right) 2 C_{i}\left(k L_{V}\right)\right]
\end{array}\right]
$$

and

$$
\left.X_{V S}=30\left[\begin{array}{l}
2 S_{i}\left(k L_{V}\right)+\cos k L_{V}\left\{2 S_{i}\left(k L_{V}\right)-S_{i}\left(2 k L_{V}\right)\right\} \\
-\sin k L_{V}\left\{2 C_{i}\left(k L_{V}\right)-C_{i}\left(2 k L_{V}\right)-C_{i}\left(\frac{2 k T^{2}}{L_{V}}\right)\right.
\end{array}\right]\right\}
$$

here

$$
L_{V}=L_{v s}-T
$$

in which $C$ is Euler's constant, $k$ is propagation constant in free space, functions $S_{i}(x)$ and $C_{i}(x)$ are the sine and cosine integrals defined as

$$
\begin{gathered}
S_{i}(x)=\int_{0}^{x} \frac{\sin (x)}{x} d x \\
C_{i}(x)=-\int_{x}^{\infty} \frac{\cos (x)}{x} d x
\end{gathered}
$$

Similarly, the impedance of the horizontal slot can be given as [23]

$$
Z_{H S}=R_{H S}+j X_{H S}
$$

where

$$
\begin{gathered}
R_{H S}=60\left[\begin{array}{l}
C+\ln \left(k L_{h s}\right)+\frac{1}{2} \sin \left(k L_{h s}\right)\left[S_{i}\left(2 k L_{h s}\right) 2 S_{i}\left(k L_{h s}\right)\right] \\
+\frac{1}{2} \cos \left(k L_{h s}\right)\left[C+\ln \frac{k L_{h s}}{2} C_{i}\left(2 k L_{h s}\right) 2 C_{i}\left(k L_{h s}\right)\right]
\end{array}\right] \text { and } \\
X_{H S}=30\left[\begin{array}{l}
2 S_{i}\left(k L_{h s}\right)+\cos k L_{h s}\left\{2 S_{i}\left(k L_{h s}\right)-S_{i}\left(2 k L_{h s}\right)\right\} \\
-\sin k L_{h s}\left\{2 C_{i}\left(k L_{h s}\right)-C_{i}\left(2 k L_{h s}\right)-C_{i}\left(\frac{2 k T^{2}}{L_{h s}}\right)\right\}
\end{array}\right]
\end{gathered}
$$

in which, $L_{v s}$ and $T=$ length and width of the vertical slot, $L_{h s}$ and $T=$ length and width of the horizontal slot, $R_{V S}$ and $X_{V S}=$ Radiation resistance and reactive component of the vertical slot, $R_{H S}$ and $X_{H S}=$ Radiation resistance and reactive component of the horizontal slot, $Z_{V S}$ and $Z_{H S}=$ Input impedance of the vertical and horizontal slot

Hence the total input impedance of the T-slot can be derived as [Figure 3(b)].

$$
Z_{T S}=\frac{Z_{V S} Z_{H S}}{Z_{V S}+Z_{H S}}
$$




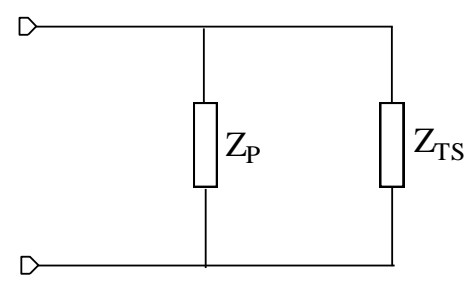

\section{Figure 4. Equivalent Circuit of the T-slot Loaded Circular Disk Patch Antenna}

The T-slot microstrip patch antenna can be considered as a parallel combination of impedance of the patch and the T-slot as shown in Figure 4, therefore the total input impedance of the T-slot loaded circular microstrip patch antenna can be derived as

$$
Z_{\text {in }}=\frac{Z_{P} Z_{T S}}{Z_{P}+Z_{T S}}
$$

Therefore, using value of input impedance from the equation (8), the reflection coefficient $(I), V S W R$ and the return loss $(R L)$ of the T-slot loaded patch antenna can be calculated as [24]

$$
\Gamma=\frac{Z_{\text {in }}-Z_{0}}{Z_{\text {in }}+Z_{0}}
$$

where, $Z_{0}$ is the input impedance of the coaxial feed (50 $\Omega$ )

$$
\begin{gathered}
V S W R=\frac{1+|\Gamma|}{1-|\Gamma|} \\
R L=20 \log |\Gamma|
\end{gathered}
$$

\section{Discussion of Results}

The proposed disk patch antenna with T-slot loaded is fabricated and measured to verify the antenna characteristics for dual band operation. The Agilent E5071C Network Analyzer is used to measure the return loss of the proposed antenna and the simulation is performed by IE3D simulator [25].

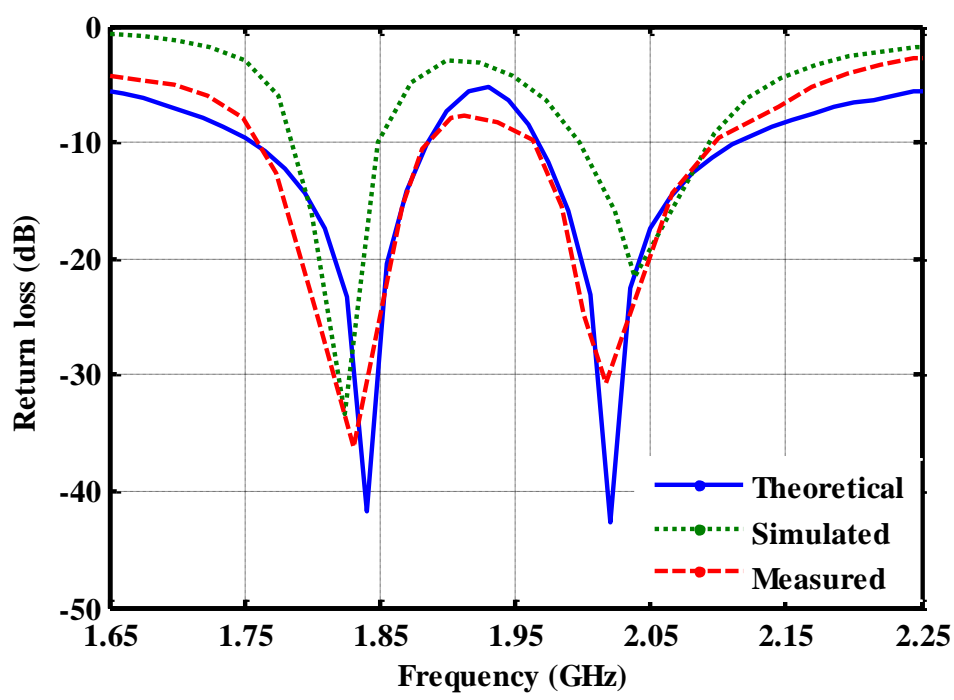

Figure 5. Variation of Return Loss with Frequency along with Theoretical, Simulated and Measured Results $\left(L_{v s}=18 \mathrm{~mm}, L_{h s}=18 \mathrm{~mm}, \mathrm{~T}=2 \mathrm{~mm}, a=\right.$ 


\section{$\left.15 \mathrm{~mm}, h=1.6 \mathrm{~mm}, \varepsilon_{r}=4.4\right)$}

The comparative plot of theoretical, simulated and measured results for T-slot loaded disk patch antenna is shown in Figure 5. It is found that the antenna resonates at two frequencies i.e., $f_{r l}=1.835 \mathrm{GHz}, f_{r 2}=2.016 \mathrm{GHz}$ and $-10 \mathrm{~dB}$ bandwidths are $6.59 \%$ and $6.89 \%$ for lower and upper resonance frequencies respectively. Calculated frequency ratio for upper to lower resonance frequency $\left(f_{r 2} / f_{r 1}\right)$ is 1.09 . It is clearly seen that measured results agree with those from theoretical and simulated results. The complete details of the proposed antenna for measured, simulated and theoretical results are summarized in Table 3 . In comparison to these reference antennas, the proposed antenna is quite compact ( $30 \times$ $\left.30 \mathrm{~mm}^{2}\right)$ in size which provides the wider bandwidth $(6.59 \%$ and $6.89 \%)$ with a small frequency ratio 1.097 .

Table 3. Calculated Bandwidth for Measured, Simulated and Theoretical Results

\begin{tabular}{|c|c|c|c|c|c|c|}
\hline \multirow{2}{*}{$\begin{array}{c}\text { Proposed } \\
\text { antenna }\end{array}$} & \multicolumn{2}{|c|}{ Lower resonance frequency } & \multicolumn{3}{c|}{ Upper resonance frequency } \\
\cline { 2 - 7 } & $\begin{array}{c}\text { Bandwidth } \\
(\mathrm{MHz})\end{array}$ & $\begin{array}{c}\text { Centre } \\
\text { Frequency } \\
(\mathrm{GHz})\end{array}$ & $\begin{array}{c}\text { Bandwidth } \\
(\%)\end{array}$ & $\begin{array}{c}\text { Bandwidth } \\
(\mathrm{MHz})\end{array}$ & $\begin{array}{c}\text { Centre } \\
\text { Frequency } \\
(\mathrm{GHz})\end{array}$ & $\begin{array}{c}\text { Bandwidth } \\
(\%)\end{array}$ \\
\hline Measured & 135 & 1.835 & 6.59 & 141 & 2.016 & 6.89 \\
Simulated & 137 & 1.82 & 6.34 & 139 & 2.03 & 6.73 \\
Theoretical & 144 & 1.84 & 7.69 & 140 & 2.02 & 6.86 \\
\hline
\end{tabular}

Figure 6 and 7 shows the variation of return loss with frequency for the different values of vertical and horizontal slot lengths respectively. From the figures, it is found that lower and upper resonance frequencies are shifted towards higher side as the vertical slot length $\left(L_{v s}\right)$ increases but their corresponding bandwidths decreases as described in Table 4. On increasing the horizontal slot length $\left(L_{h s}\right)$ lower and upper resonance frequencies are shifted towards higher side and its corresponding bandwidths increases and the detail observations are summarized in Table 5. These changes are observed in the figures due to the variation in impedance of vertical and horizontal slots as derived from the equations (5) and (6).

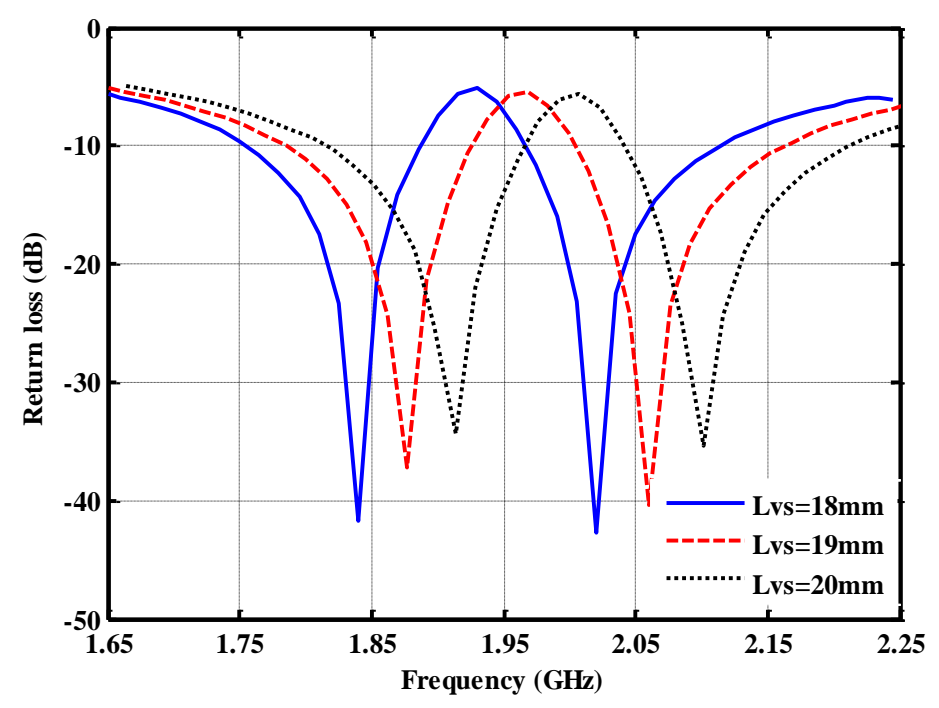

Figure 6. Variation of Returns Loss with Frequency for Different Values of Vertical Slot Length $\left(L_{v s}\right)$ 


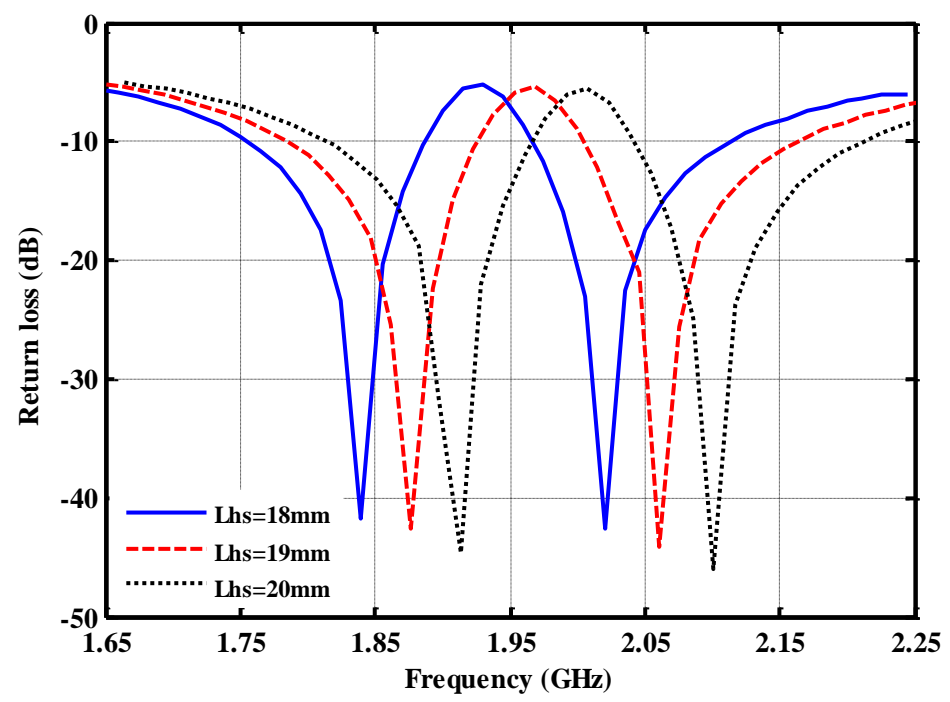

Figure 7. Variation of Returns Loss with Frequency for Different Values of Horizontal Slot Length $\left(L_{h s}\right)$

Table 4. Calculated Bandwidth for Different Values of Vertical Slot Length

\begin{tabular}{|c|c|c|c|c|c|c|}
\hline \multirow{2}{*}{$\begin{array}{c}\text { Vertical slot } \\
\text { length } \\
\left(\mathrm{L}_{\mathrm{vs}}\right) \mathrm{mm}\end{array}$} & \multicolumn{3}{|c|}{ Lower resonance frequency } & \multicolumn{3}{|c|}{ Upper resonance frequency } \\
\hline & $\begin{array}{c}\text { Bandwidth } \\
(\mathrm{MHz})\end{array}$ & $\begin{array}{c}\text { Centre } \\
\text { Frequency } \\
(\mathrm{GHz})\end{array}$ & $\begin{array}{c}\text { Bandwidth } \\
(\%)\end{array}$ & $\begin{array}{c}\text { Bandwidth } \\
(\mathrm{MHz})\end{array}$ & $\begin{array}{c}\text { Centre } \\
\text { Frequency } \\
(\mathrm{GHz})\end{array}$ & $\begin{array}{c}\text { Bandwidth } \\
(\%)\end{array}$ \\
\hline 18 & 144 & 1.84 & 7.69 & 140 & 2.02 & 6.86 \\
\hline 19 & 137 & 1.88 & 7.00 & 139 & 2.06 & 6.73 \\
\hline 20 & 123 & 1.92 & 6.34 & 134 & 2.10 & 6.60 \\
\hline
\end{tabular}


Table 5. Calculated Bandwidth for Different values of Horizontal Slot Length

\begin{tabular}{c|c|c|c|c|c|c}
\hline \multirow{2}{*}{$\begin{array}{c}\text { Horizontal } \\
\text { slot length } \\
\left(\mathrm{L}_{\mathrm{hs}}\right) \mathrm{mm}\end{array}$} & \multicolumn{2}{|c|}{ Lower resonance frequency } & \multicolumn{3}{|c}{ Upper resonance frequency } \\
\cline { 2 - 7 } & $\begin{array}{c}\text { Bandwidth } \\
(\mathrm{MHz})\end{array}$ & $\begin{array}{c}\text { Centre } \\
\text { Frequency } \\
(\mathrm{GHz})\end{array}$ & $\begin{array}{c}\text { Bandwidth } \\
(\%)\end{array}$ & $\begin{array}{c}\text { Bandwidth } \\
(\mathrm{MHz})\end{array}$ & $\begin{array}{c}\text { Centre } \\
\text { Frequency } \\
(\mathrm{GHz})\end{array}$ & $\begin{array}{c}\text { Bandwidth } \\
(\%)\end{array}$ \\
\hline 18 & 144 & 1.84 & 7.69 & 140 & 2.02 & 6.86 \\
19 & 170 & 1.89 & 9.16 & 162 & 2.07 & 7.65 \\
20 & 202 & 1.94 & 10.58 & 183 & 2.12 & 8.41 \\
\hline
\end{tabular}

Figure 8 and 9 shows the variation of return loss with frequency for the different values of slots and substrate thickness respectively.

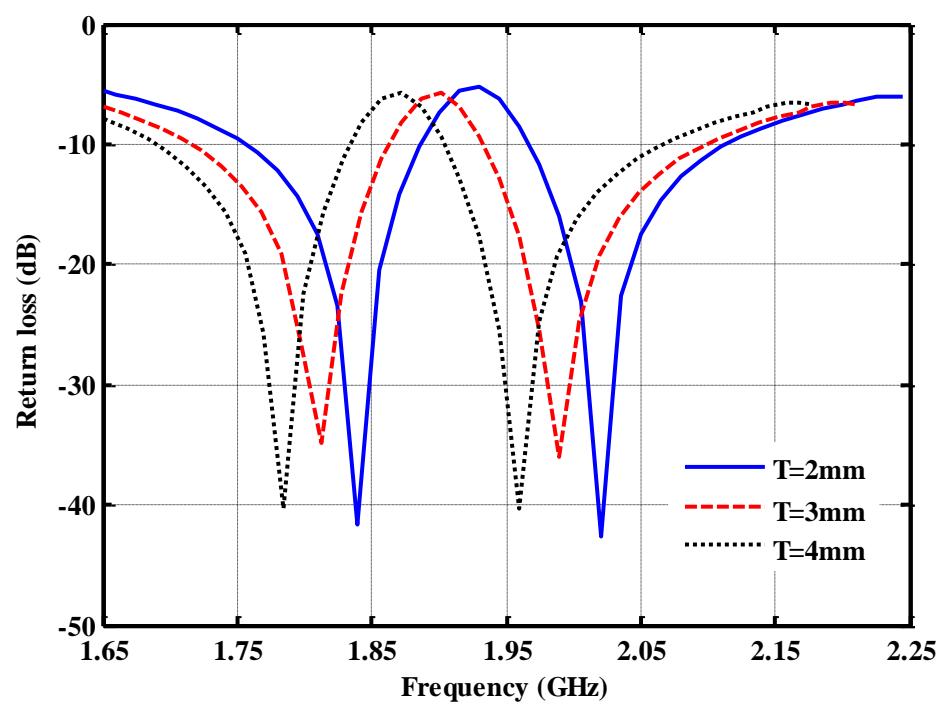

\section{Figure 8. Variation of Returns Loss with Frequency for Different Values of Slot Thickness}

From Figure 8, it is found that lower and upper resonance frequencies are shifted towards lower side as the slot thickness $(T)$ increase, this also increases the corresponding bandwidths and detail description is given in Table 6 .

Table 6. Calculated Bandwidth for Different Values of Slot Thickness

\begin{tabular}{c|c|c|c|c|c|c}
\hline \multirow{2}{*}{$\begin{array}{c}\text { Slot } \\
\text { thickness }\end{array}$} & \multicolumn{2}{|c|}{ Lower resonance frequency } & \multicolumn{3}{c}{ Upper resonance frequency } \\
\cline { 2 - 6 }$(\mathrm{T}) \mathrm{mm}$ & $\begin{array}{c}\text { Bandwidth } \\
(\mathrm{MHz})\end{array}$ & $\begin{array}{c}\text { Centre } \\
\text { Frequency } \\
(\mathrm{GHz})\end{array}$ & $\begin{array}{c}\text { Bandwidth } \\
(\%)\end{array}$ & $\begin{array}{c}\text { Bandwidth } \\
(\mathrm{MHz})\end{array}$ & $\begin{array}{c}\text { Centre } \\
\text { Frequency } \\
(\mathrm{GHz})\end{array}$ & $\begin{array}{c}\text { Bandwidth } \\
(\%)\end{array}$ \\
\hline 2 & 144 & 1.84 & 7.69 & 140 & 2.02 & 6.86 \\
3 & 150 & 1.80 & 8.40 & 146 & 2.00 & 7.44 \\
4 & 159 & 1.78 & 8.98 & 161 & 1.98 & 8.04 \\
\hline
\end{tabular}

On increasing the height of substrate $(h)$, the lower and upper resonance frequencies are shifted towards higher side, this causes increase in inductance while decrease in capacitance. From the Figure 9, 


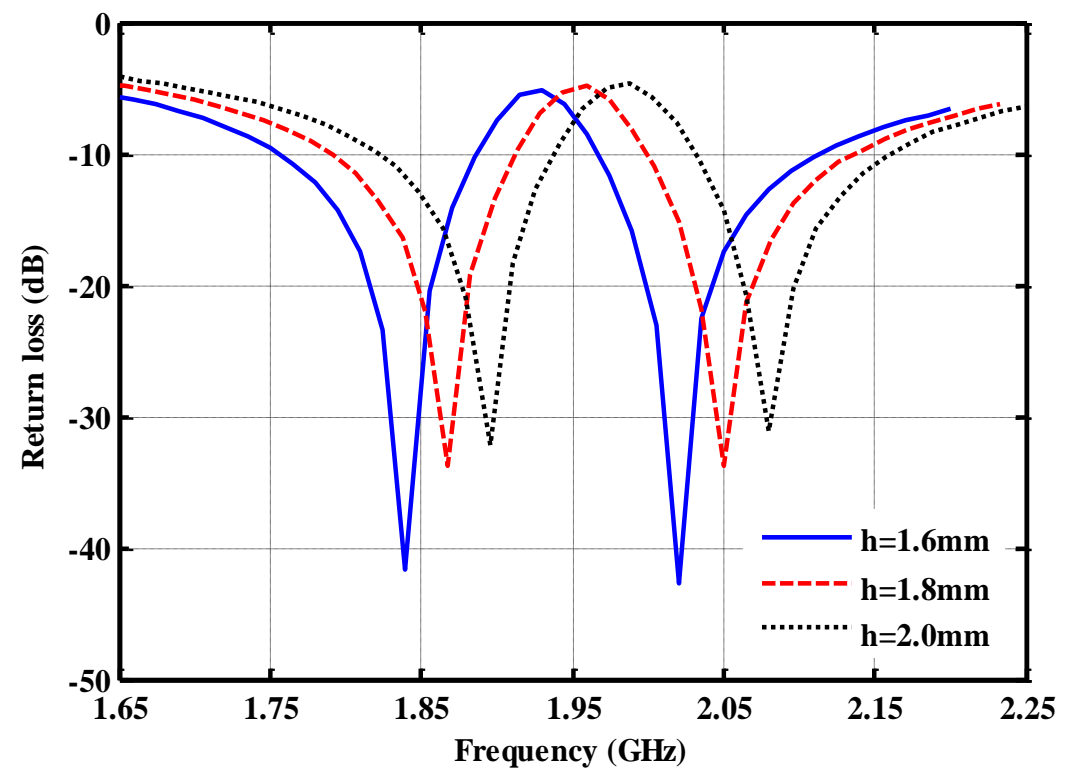

Figure 9. Variation of Returns Loss with Frequency for Different Values of Substrate Thickness $(h)$

It is observed that the bandwidths of the antenna decreases. The variation of bandwidth for different thickness of the substrate is given in Table 7 .

Table 7. Calculated Bandwidth for Different values of Substrate Thickness

\begin{tabular}{c|c|c|c|c|c|c}
\hline \multirow{2}{*}{$\begin{array}{c}\text { Substrate } \\
\text { thickness } \\
\text { (h) } \mathrm{mm}\end{array}$} & \multicolumn{2}{|c|}{ Lower resonance frequency } & \multicolumn{3}{c}{ Upper resonance frequency } \\
\cline { 2 - 6 } & $\begin{array}{c}\text { Bandwidth } \\
(\mathrm{MHz})\end{array}$ & $\begin{array}{c}\text { Centre } \\
\text { Frequency } \\
(\mathrm{GHz})\end{array}$ & $\begin{array}{c}\text { Bandwidth } \\
(\%)\end{array}$ & $\begin{array}{c}\text { Bandwidth } \\
(\mathrm{MHz})\end{array}$ & $\begin{array}{c}\text { Centre } \\
\text { Frequency } \\
(\mathrm{GHz})\end{array}$ & $\begin{array}{c}\text { Bandwidth } \\
(\%)\end{array}$ \\
\hline 1.6 & 144 & 1.84 & 7.69 & 140 & 2.02 & 6.86 \\
1.8 & 126 & 1.89 & 6.48 & 123 & 2.06 & 5.82 \\
2.0 & 117 & 1.94 & 6.38 & 114 & 2.14 & 5.74 \\
\hline
\end{tabular}

It is observed form the figures and tables that bandwidth varies on the variation of slot and substrate thickness. The variations in slots and substrate thickness are observed because input impedance of the slots varies whereas input impedance of the substrate thickness varies with the relative permeability which inversely changes the resonance frequencies of the radiating patch. These changes are observed in slots and substrate thickness from the equations (5) and (6).

Figure 10 and 11, shows the ratio of resonance frequencies $\left(f_{r 2} / f_{r 1}\right)$ for different values of vertical and horizontal slot length. It is found that the frequency ratio decreases on increasing the vertical slot length as well as horizontal slot length.

Figure 12 and 13, shows the ratio of resonance frequencies $\left(f_{r 2} / f_{r 1}\right)$ for different values of slot and substrate thickness. It is observed that the frequency ratio increases on increasing the both slot and substrate thickness. 


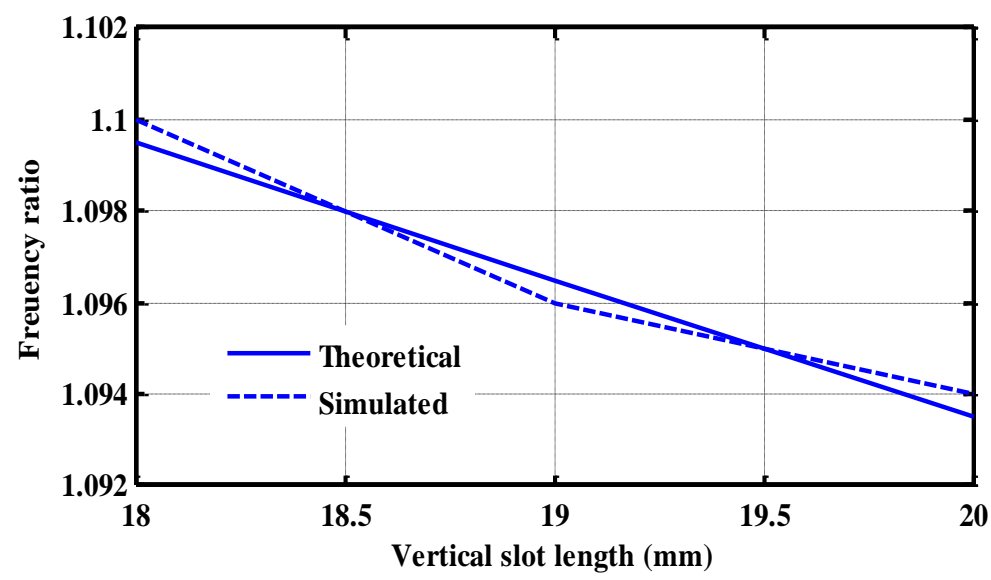

Figure 10. Variation of Frequency Ratio for Different Values of Vertical Slot Length $\left(L_{v s}\right)$

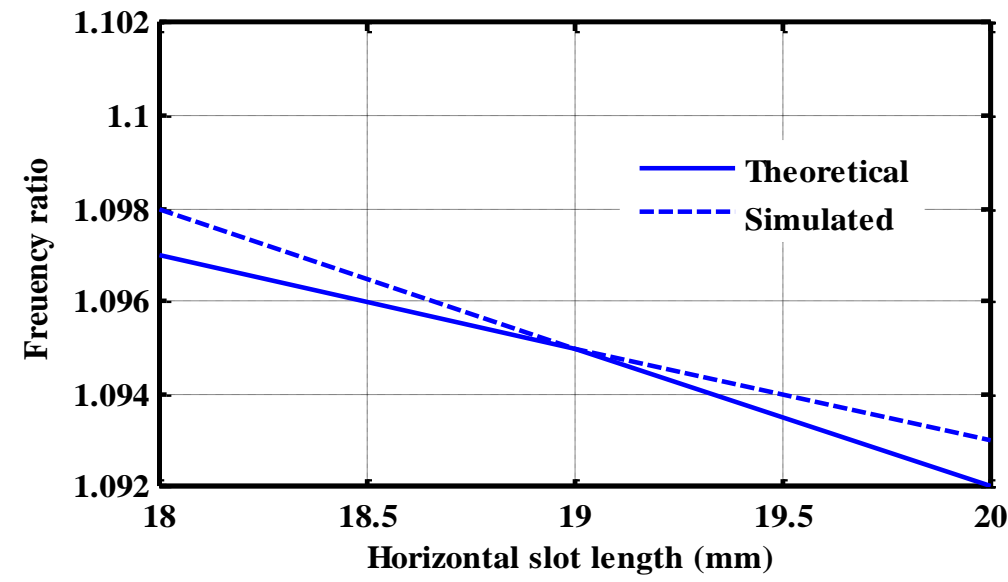

Figure 11. Variation of Frequency Ratio for Different Values of Horizontal Slot Length $\left(L_{h s}\right)$

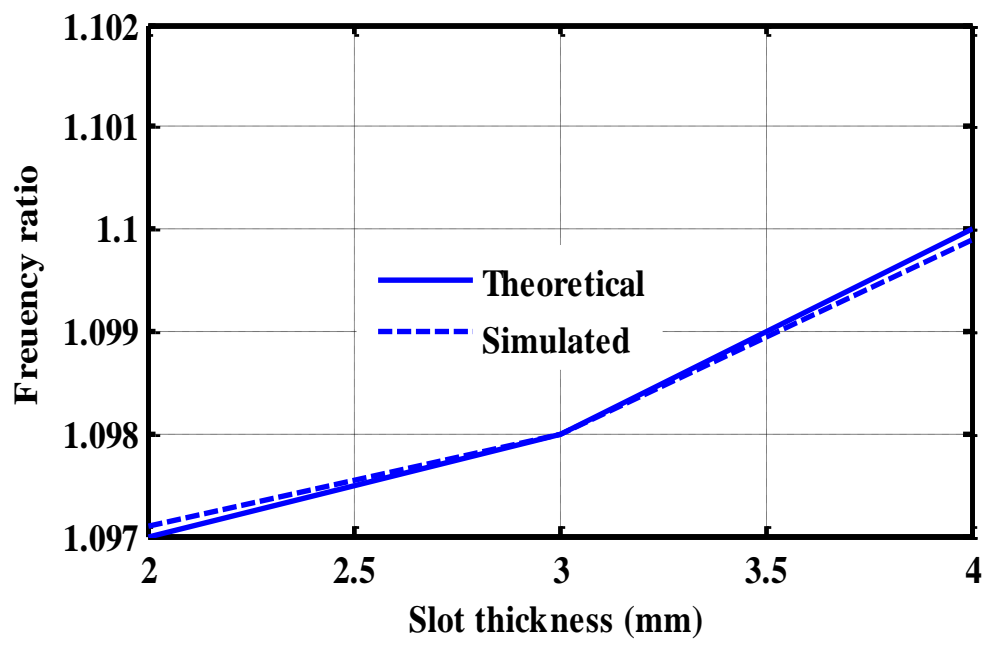

Figure 12. Variation of Frequency Ratio for Different Values of Slot Thickness $(T)$ 


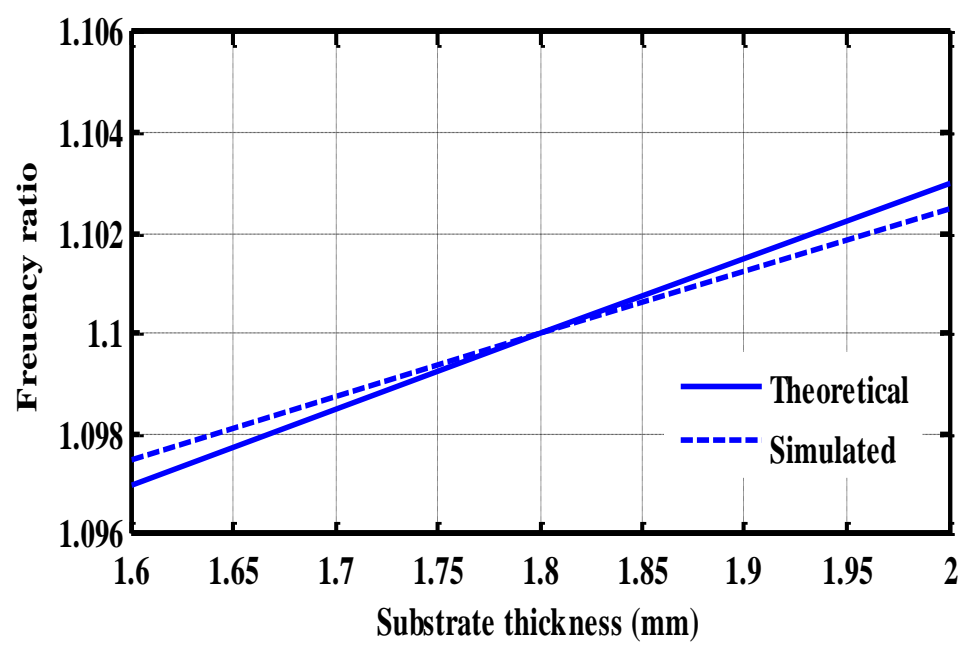

Figure 13. Variation of Frequency Ratio for Different Values of Substrate Thickness $(h)$

The gain and efficiency of the proposed antenna are shown in Figure 14 and 15. From the figures, it is observed that the peak gain of the antenna is $5.78 \mathrm{dBi}$ at $1.84 \mathrm{GHz}$ and $6.52 \mathrm{dBi}$ at $2.02 \mathrm{GHz}$ for theoretical result whereas for simulated result is $4.28 \mathrm{dBi}$ and $5.12 \mathrm{dBi}$ at lower and higher resonance frequencies respectively. The efficiency of the proposed antenna is $62.17 \%$ (theoretical) and $54.4 \%$ (simulated) at lower resonance whereas $76.42 \%$ (theoretical) and $66.86 \%$ (simulated) at upper resonance frequency.

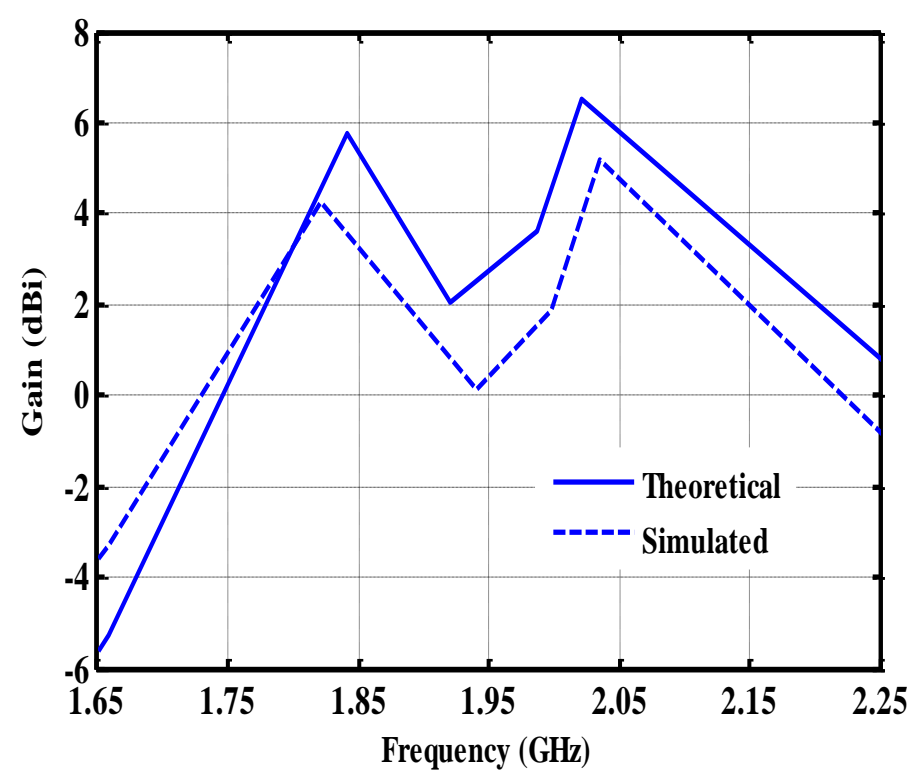

Figure 14. Theoretical and Simulated Gain for T-slot Loaded Circular Patch Antenna 


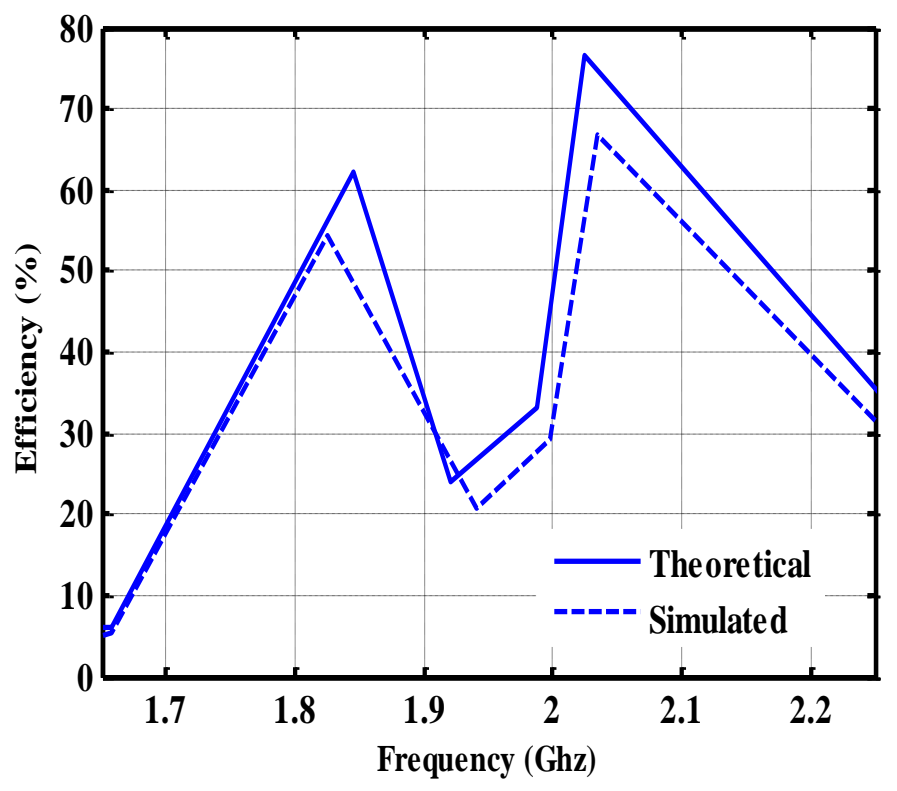

Figure 15. Theoretical and Simulated Efficiency for T-slot Loaded Circular Patch Antenna

The proposed antenna gives the linear polarized radiation pattern for the lower and upper resonance frequencies as shown in Figures 16 and 17. The 3-dB beamwidths are calculated as $75^{\circ}$ (theoretical) and $73.5^{\circ}$ (simulated) at the lower resonance and $84.4^{\circ}$ (theoretical) and $80.5^{\circ}$ (simulated) at the upper resonance frequency. It is noted that the theoretical and simulated radiation patterns are in close agreement with each other.

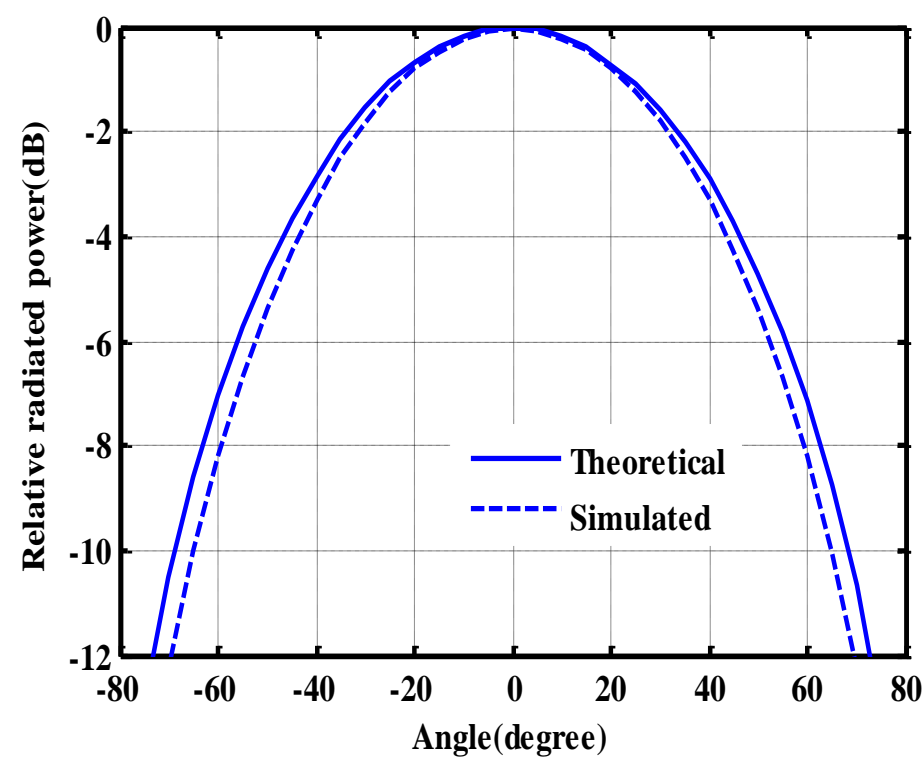

Figure 16. Radiation Pattern of Lower Resonance Frequency for T-slot Loaded Circular Patch Antenna 


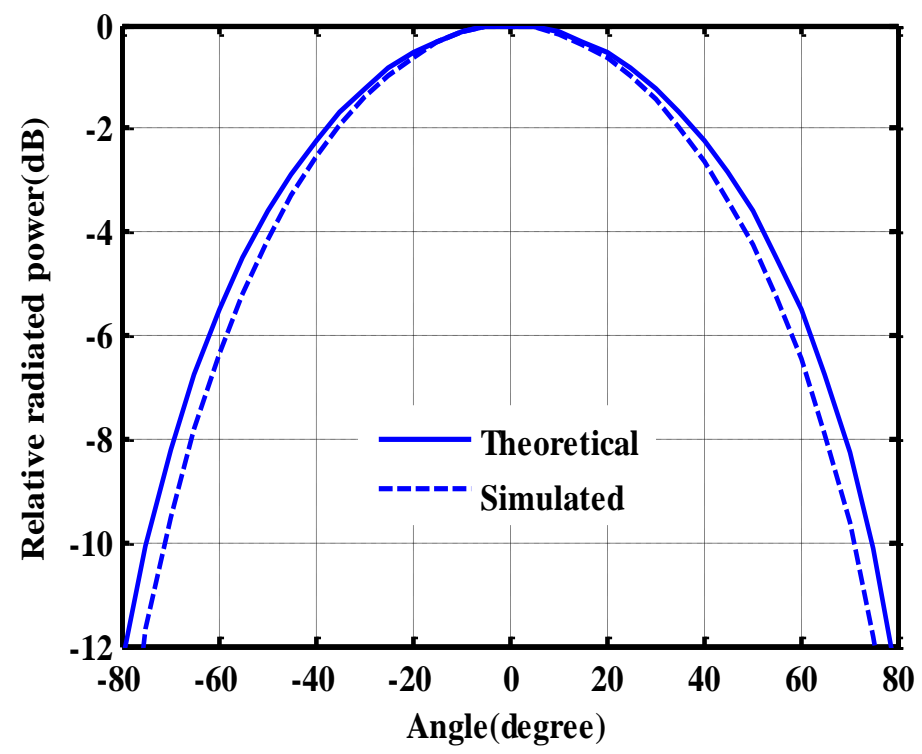

\section{Figure 17. Radiation Pattern of Upper Resonance Frequency for T-slot Loaded Circular Patch Antenna}

\section{Conclusion}

The characteristics of a dual band disk patch antenna with T-slot have been proposed and its theoretical and simulated results are verified with measured results. From the analysis it is concluded that T-slot loaded circular patch antenna operates at two resonance frequencies $1.84 / 2.02 \mathrm{GHz}$ with small frequency ratio of 1.09 . The resonance frequencies are highly dependent on the slot dimensions and substrate thickness. Design parameters of T-slot play crucial role in controlling bandwidth as well as separation of resonances. The proposed antenna is suitable for DCS-1800, PCS-1900 and IMT-2000 applications.

\section{Acknowledgement}

One of the authors (SV) thankfully acknowledges the financial assistance (SRF) provided by University Grant Commission (Government of India), New Delhi for the research work.

\section{References}

[1] R. Garg, P. Bhartia, I. Bahl and A. Ittipiboon, "Microstrip Antenna Design Handbook", Artech House Inc., (2001).

[2] K. L. Wong, "Compact and Broadband Microstrip Antennas", New York: Wiley, (2002).

[3] Z. Miao, C. Huang, X. Ma, M. Pu, X. Ma, Q. Zhao and X. Luo, "Design of a patch antenna with dualband radar cross-section reduction", Microwave Optical Technology Letters, vol.54, (2012), pp.25162520.

[4] J. Ghalibafan, A. R. Attari and F. H. Kashani, "A new dual-band microstrip antenna with U-shaped slot", Progress in Electromagnetic Research C, vol.12, (2010), pp.215-223.

[5] Y.-Y. Liou, J.-S. Row and T.-R. Chen, "Dual-frequency design of a shorted triangular patch Antenna", Microwave Optical Technology Letters, vol.48, (2006), pp.749-751.

[6] M. Boney, S. K. A. Rahim, R. Dewan and B. M. Sa'ad, "Dual band trapezoidal antenna with partial ground and meander line feed for GPS and WIMAX applications", Microwave Optical Technology Letters, vol.55, (2014), pp.497-502.

[7] A, Gupta, M. P. Abegaonkar, A. Basu and S. K. Koul, "A tunable high impedance surface and its application to dual-band microstrip antenna", Progress in Electromagnetic Research C, vol.43, (2013), pp.231-246. 
[8] J. A. Ansari, A. Mishra, N. P. Yadav, P. Singh and B. R. Vishwakarma, "Analysis of L-shaped slot loaded circular disk patch antenna for satellite and radio telecommunication", Wireless Personal Communication, vol.70, (2013), pp 927-943.

[9] J. J. Tiang, M. T. Islam, N. Misran and J. Singh Mandeep, "A rounded corner triangular patch antenna for dual frequency application", Microwave Optical Technology Letters, vol.56, (2014), pp.69-72.

[10] R. Dewan, S. K. A. Rahim, F. Malek, S. F. Ausordin, A. A. Yusuf and S. N. Azemi, "A dual-band array antenna using dome-shaped radiating patches", Microwave Optical Technology Letters, vol.55, (2013), pp.2680-2686.

[11] S. Babau and R. Vishvakarma, "Analysis of inclined slot-loaded patch antenna for dual-band operation", Microwave Optical Technology Letters, vol.48, (2006), pp.2436-2441.

[12] J.-Y. Sze, C.-I G. Hsu and S.-C. Hsu, "Studies of small dualband annular-ring slot antenna with a pair of implanted spur-like slits", Microwave Optical Technology Letters, vol.49, (2007), pp.1578-1581.

[13] A. K. Singh and M. K. Meshram, "Slot-loaded shorted patch for dual-band operation", Microwave Optical Technology Letters, vol.50, (2008), pp.1010-1017.

[14] L. Zhang, Y.-C. Jiao, K. Song and F.-S. Zhang, "Compact dual-frequency double T-shaped slot antenna for RFID application”, Microwave Optical Technology Letters, vol.51, (2009), pp.1755-1757.

[15] W. Liao and Q.-X. Chu, "Dual-band circularly polarized microstrip antenna with small frequency ratio", Progress in Electromagnetic Research Letters, vol.15, (2010), pp.145-152.

[16] P. Nayeri, K.-F. Lee, A. Z. Elsherbeni and F. Yang, "Dual-band circularly polarized antennas using stacked patches with asymmetric U-slots", IEEE Antennas Wireless Propagation Letters, vol.10, (2011), pp.492-495.

[17] J. A. Ansari, A. Mishra, N. P. Yadav, P. Singh and B. R. Vishvakarma, "Analysis of W- Slot Loaded Patch Antenna for Dual Band Operation”, International Journal of Electronics and Communications (AEÜ), vol.66, (2012), pp.32-38

[18] M. Ali, B. A. Khawaja, M. A. Tarar and M. Mustaqim, "A dual band U-slot printed antenna array for LTE and WIMAX applications", Microwave Optical Technology Letters, vol.55, (2013), pp.2879-2883.

[19] Z.-J. Jin and T.-Y. Yun, "Compact dual-band slot antenna with capacitor loading", Microwave and Optical Technology Letters, vol.56, (2014), pp.1653-1658.

[20] A. K. Bhattacharjee, "Equivalence of radiation properties of square and circular microstrip patch antenna", IEEE Transactions on Antennas and Propagation, vol.38, (1990), pp.1710-1711.

[21] L. C. Chen, "Resonant frequency of circular disk printed circuit antenna", IEEE Transactions on Antennas and Propagation, vol.25, (1997), pp.595-596.

[22] E. A. Wolf, “Antenna Analysis", Narwood, MA: Artech House, (1988).

[23] S. S. Sharma and B. R. Vishvakarma, "Analysis of slot loaded rectangular microstrip patch antenna", Indian Journal of Radio Space and Physics, vol.34, (2005), pp.424-430.

[24] A. G. Dernery and A. G. Lind, "Extended analysis of rectangular microstrip resonator antenna," IEEE Transactions on Antennas and Propagation, vol.27, (1979), pp.846-849.

[25] Zeland Software Inc., IE3D simulation software, version 14.05, (2008).

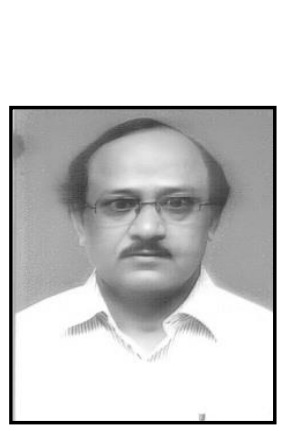

\section{Authors}

J. A. Ansari, he was born in 1966 in Gahmar, Ghazipur (U.P.), India. He received the B.Sc. and B.Tech. degrees in electronics and telecommunications from University of Allahabad, Allahabad, India, the M.Tech. degree in communication systems from the Institute of Technology, Banaras Hindu University (BHU), Varanasi, India, in 1991, and the Ph.D. degree from Mahatma Gandhi Chitrakoot Gramodaya Vishvavidyalaya, Chitrakoot (Satna), India, in 2000. He has published 90 papers in different national and international journals and conference proceedings. His current area of research is microstrip antenna, millimeter wave, and fiber optics. He is presently working as a Reader with the Department of Electronics and Communication, University of Allahabad. 


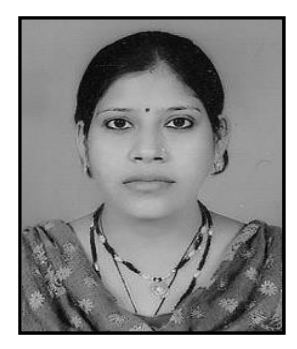

Sapna Verma, she was born in Bhopal, (M.P.), India, in September 1983. She received the B.Tech. in Electronics \& Communication Engineering from Institute of Engineering and Technology, Bundelkhand University, Jhansi, UP, India in 2006. She completed M.Tech. in Digital Communication from Bundelkhand Institute of Engineering and Technology (UP Technical University, Lucknow), Jhansi, India in 2009. She is currently working towards her Ph.D degree from department of Electronics and Communication, J K Institute of Applied Physics and Technology, University of Allahabad, Allahabad, UP, India. Her research interests include microstrip antenna design, satellite communication etc. She is also received UGC, New Delhi, India fellowship in PG and research. She has also teaching experience in JIET, Jind, Haryana, India. 